experience in examining the eyes of men who have returned from the front.

The conditions under which war is now carried on have so changed that I believe the standard of vision suggested by the Committee, and which appears to have been adopted by the Army Council, will exclude from A1 a very large number of men. There must be thousands of men whose vision does not reach this standard who have done very good work in the firing line.

Taking one of my case books containing the reports of 650 men who have been at the front. I find there are 22 non-com. officers whose vision in B.E. is $6 / 60$ or less. These must all have done good work to have been granted their "stripes." There is still a larger number whose vision in B.E. is below 6/24. There is, of course, a very much larger number of men whose vision is equally deficient, but who have not got promotion.

To show what can be done I will give particulars of one man, viz. :

Rfn. G.-R.E. $6 / 60$ c. -3 D. cyl. $10^{\circ}=6 / 12$ partly.

L.E. $6 / 24$ partly -4 D. cyl. $160^{\circ}=6 / 9$.

$\mathrm{He}$ is a sniper and first class bomb instructor. He tells me that when sniping he took his glasses off, and could make good practice.

The testing of men's sight by types is very fallacious. The real test of a man's limitations can only satisfactorily be carried out by his instructors. The intelligence of a man has much to do with the amount he can see, and mental amblyopia is not very uncommon.

I would make the following suggestions :-

Men with active disease, and very high myopia, should be rejected.

Men who can see 6/60 with B.E. without glasses should provisionally be placed in A. If the sight can be improved with glasses, these should be ordered, and a report sent to the C.O. as to the condition of the man's sight and his probable limitations.

When the army instructors take them in hand, I believe that in actual practice they will be in a far better position to put them into the proper categories than the ophthalmic specialists.

Yours, etc.,

H. H. TAYLOR, F.R.C.S., Major.

O. i.c. Ophthalmic Centre of the District of Sussex.

\title{
ATROPIN IN CATARACT EXTRACTION
}

To the Editor BRITISH JouRnal of OpHThalmology

SiR,-In the December number of THE BRITISH Jouknal OF OPHTHALMOLOGY you were good enough to publish a short note 
of mine in reference to a practice which I had recently adopted in performing the combined operation for cataract, of introducing a drop or two of sterilized sulphate of atropin into the conjunctival sac after the speculum had been inserted, and at once proceeding to make the usual section. The advantages appeared to me to be that, while one was operating on the cataract under quite normal conditions, before the completion of the operation the pupil was observed to be dilating widely and circularly under the influence of the mydriatic, which, under these circumstances, reached the iris in considerable concentration, and it would be found to remain dilated to the maximum extent without further use of mydriatic for the first three or four days of convalescence. I suggested that possibly other operators might be inclined to test the efficacy of this method, and at a later date express their opinions upon it.

In the February number of the Journal, Dr. Ernest Thomson refers to the quite different method of dilating the pupil either on the day preceding or a few hours before the operation. That this method of operating had been adopted by others was well known to me, and I have indeed myself, in years gone by, made a trial of it. It is obviously quite a different method from that which I suggested in $\mathrm{my}$ recent note, and in my experience in no way relieved the operator of the necessity of frequent instillations of mydriatic in the days immediately succeeding the operation.

Mr. S. Johnson Taylor in his letter has equally missed the point of my suggestion, and leaves me nothing to answer. He dilates on the question of operating for cataract after dilatation of the pupil with mydriatic; on the value of eserin applied after simple extraction of cataract ; on the well-worn subject of the comparative advantages of extraction with and without iridectomy, and finally expresses the opinion that the number of really good ophthalmic operators is small. I do not propose to follow him into any of these interesting fields. When other operators, if they think it worth while, have a practical experience of the idea which I suggested in my article, I trust the British JOURNAL OF OPHTHALMOLOGY will be able to find space for the expression of their opinions on its advantages or its disadvantages.

Wimpole Street, W.,

Yours, etc.,

J. Herbert Fisher. February 4, 1918. 